\title{
System of single-piece flow case hardening for high volume production
}

\author{
E. Wołowiec-Korecka a,^, M. Korecki c, W. Stachurski b, P. Zgórniak b, \\ J. Sawicki a, A. Brewka c, M. Sut c, M. Bazel c \\ a Institute of Materials Science and Engineering, Lodz University of Technology, \\ ul. Stefanowskiego 1/15, 90-924 Łódź, Poland \\ b Institute of Machine Tools and Production Engineering, Lodz University of Technology, \\ ul. Stefanowskiego 1/15, 90-924 Łódź, Poland \\ c Seco/Warwick SA, ul. Sobieskiego 8, 66-200 Świebodzin, Poland \\ * Corresponding e-mail address: emilia.wolowiec@p.lodz.pl
}

\section{ABSTRACT}

Purpose: Purpose of this paper is development of single-piece flow system to precision thermal treatment of parts of mechanical gear using a short-pulse low-pressure carburising technology (developed for a new large-chamber furnace).

Design/methodology/approach: Sections of the article discuss the novel constructions of the device in which parts being carburised flow in a stream, as well as the low-pressure carburising experiment.

Findings: The method has been found proper carburised layers on typical gear used in automotive industry.

Research limitations/implications: The short-pulse low-pressure carburising technology needs further investigation to fully understand its all mechanisms.

Practical implications: The device resulting from the experiment can be a fully robotised part of a production line which can be included in a system of automatic control of a production process.

Originality/value: The device resulting from the experiment is only known solution on the world.

Keywords: Heat treatment; Thermo-chemical treatment; Case hardening; Vacuum carburizing; High pressure gas quenching; Hardening distortion; Single-piece flow

\section{Reference to this paper should be given in the following way:}

E. Wołowiec-Korecka, M. Korecki, W. Stachurski, P. Zgórniak, J. Sawicki, A. Brewka, M. Sut, M. Bazel, System of single-piece flow case hardening for high volume production, Archives of Materials Science and Engineering 79/1 (2016) 37-44.

\section{MATERIALS MANUFACTURING AND PROGESSING}

\section{Introduction}

The objective of the modern case hardening technology is obtaining repeatable, precisely planned parameters of the hardened layer and limiting to the minimum the negative phenomena that cause dimensional changes after quenching, with simultaneous identification of the character and extent of these changes. Low-pressure 
carburising with subsequent quenching is one of the methods aiming at achieving that objective, but next to many advantages it has also certain shortcomings that weaken the potential residing in that method.

Case hardening of steel elements based on carburising consists in diffused introduction of carbon from the surface deep into the material with subsequent quenching of the layer so created. The result is an element with high hardness, abrasion-resistant surface and elastic core that can transfer high impact loads. A classic example of application of this technology are drive transmission elements such as wheels, pinions, transmission gear elements, steering system elements, etc.

Carburising is one of the most widespread heat treatment processes, applied to billions of elements each year and having a significant impact both on quality and production cost of finished elements. The leader in this discipline is the automotive industry which is very sensitive to both the above listed parameters. It demands increasingly higher quality and efficiency and at the same time it also wants to reduce costs.

It is characteristic that heat treatment introduces dimensional deformations of elements. It is caused mainly by changes in volume of the steel structure as a result of martensitic transformation and irregularity of process parameters during heating and, especially, quenching. What may also be of significance is the non-uniform structure of steel and released stresses that were created during machining. The extent of distortions depends also on geometry of a given element. The proper geometry of the wheel (particularly of its teeth) has crucial impact on its working parameters, such as lifetime, efficiency (energy losses), vibrations and noise and therefore quenching distortions are in most cases corrected using appropriate methods (e.g. grinding). Correction of quenching distortions is one of the most expensive processes since it requires application of very high dimensional accuracy and using expensive tools for working with a material with hardness of ca. $64 \mathrm{HRC}$ and the excesses to be removed reach $0.2 \mathrm{~mm}$ or more.

The analysis of quenching distortion removal costs carried out in 1995 by Institut fur Werkstofftechnic for the German industry established their value at ca. 850 million euro per year in the automotive and transmission gear segment and 1 billion euro per year in the bearing industry [1]. When transposing the above data onto the global industry with taking into account a 20 -year production growth it can be estimated that the current value of these costs is at the level of ca. 20 billion euro. It constitutes a tremendous burden on the industry.

\section{Modern thermal and thermo-chemical treatment systems}

The case hardening process is carried out in vast majority of cases using the carburising technology in endothermal atmosphere and quenching in oil in atmospheric furnaces. Depending on the efficiency there are used chamber furnaces (of the sealed quench type) and furnaces for continuous operation: pusher-type furnaces, rotary furnaces and roller furnaces. In the mass-production industry, for the purposes of primary production there are used continuous type furnaces that provide the highest efficiencies.

Carburisation in atmospheres is a process that has been known for tens of years and is well-controlled using oxygen sensors or gas analysers. However, its nature entails an important disadvantage that cannot be removed. It consists in oxidation along the limits of austenite grains caused by presence of oxidizing gases $\left(\mathrm{CO}_{2}, \mathrm{H}_{2} \mathrm{O}, \mathrm{O}_{2}\right)$ in the atmosphere. This forces the necessity to grind the surface in order to remove the hazardous structures, leading to additional costs.

The transfer of carbon in endothermal atmosphere is not characterized by high efficiency. This results in the necessity to provide a large volume of atmosphere to the furnace, counted in tens of $\mathrm{m}^{3} / \mathrm{h}$, depending on the furnace size and surface carburised. The costs are related not only to the significant amounts of agent consumed (typically $\mathrm{CH}_{4}, \mathrm{C}_{3} \mathrm{H}_{8}$ or $\mathrm{CH}_{3} \mathrm{OH}$ ) but also energy losses and emission of gases and energy. What is also of significance to the environment is the flammability and explosiveness of the furnace atmosphere and the hazard related thereto that requires application of rigorous safety and environment protections regulations.

Quenching is an important stage in the case hardening process. It is usually done in oil. Oil is a common and wellknown quenching medium and it has well-known disadvantages resulting from the 3-phase character of cooling, various cooling rates and lack of any possibility of controlling the process. When taking into account that each of the phases appears at various times and in different place of the element quenched it is obvious that there occur major and unique distortions related to quenching in oil [2-8]. Another issue is the necessity to wash the elements post-quenching at dedicated washing stations where various chemicals are used, which becomes less and less acceptable within the scope of environment protection regulations.

The furnaces for continuous operation are powerful devices, the linear lengths of which reach up to several 
dozen metres and the surface area of the whole such system is measured in hundreds and thousands of square metres. The size of these devices results in their poor process and operation dynamics. Any change in process parameters and stabilization of conditions takes hours and the deactivation of furnace and its subsequent re-activation takes even weeks in case of the largest of these devices. Any stoppage or interruption in operation is related to significant energy losses and production losses.

In response to the shortcomings of the traditional case hardening technology, in 1970s and 1980s there was created the low-pressure carburisation (LCP) technology and high pressure gas quenching (HPGQ) technology [9]. In 1990s it was perfected enough to start installing the devices employing it in the industry, including the massproduction industry. Currently the LPC and HPGQ technologies employed in low-pressure furnaces are successfully replacing the traditional devices. There are available furnaces for batch production, single- and two- chamber, furnaces for semi-continuous production and modular systems for mass production [10-18].

Low-pressure carburising has overcome all the weaknesses of endothermal carburisation and introduced many new possibilities. The oxidation along the limits of austenite grains has been eliminated in view of the complete lack of oxygen in carboniferous gases, the carbon transfer efficiency was multiplied by about 20, bringing about a significant reduction in atmosphere consumption, and, additionally, the atmosphere inside the furnace is neither flammable nor explosive thanks to its low density. Moreover, the LPC process is characterised by unmatched capability of atmosphere penetration and regular carburisation of details with shapes that cause difficulties in access (non-through holes) and densely packed batches, as well as by giving the possibility of significant increase in temperature resulting in making the carburisation time even as much as $4-5$ times shorter after changing the temperature from $925^{\circ} \mathrm{C}$ to $1040^{\circ} \mathrm{C}$ (Table 1.).

Table1.

Carburisation time depending on the temperature for the $16 \mathrm{MnCr} 5$ steel and $0.35 \% \mathrm{C}$ layer thickness criterion [19]

\begin{tabular}{ccccccc}
\hline \multirow{2}{*}{$\begin{array}{c}\text { ayer } \\
\mathrm{mm}\end{array}$} & $925^{\circ} \mathrm{C}$ & $950^{\circ} \mathrm{C}$ & $980^{\circ} \mathrm{C}$ & $1000^{\circ} \mathrm{C}$ & $1020^{\circ} \mathrm{C}$ & $1040^{\circ} \mathrm{C}$ \\
\cline { 2 - 7 } & $1 \mathrm{~h} 23 \mathrm{~m}$ & $0 \mathrm{~h} 57 \mathrm{~m}$ & $0 \mathrm{~h} 39 \mathrm{~m}$ & $0 \mathrm{~h} 30 \mathrm{~m}$ & $0 \mathrm{~h} 24 \mathrm{~m}$ & $0 \mathrm{~h} 19 \mathrm{~m}$ \\
\hline 0.50 & $5 \mathrm{~h} 30 \mathrm{~m}$ & $3 \mathrm{~h} 50 \mathrm{~m}$ & $2 \mathrm{~h} 35 \mathrm{~m}$ & $2 \mathrm{~h} 00 \mathrm{~m}$ & $1 \mathrm{~h} 35 \mathrm{~m}$ & $1 \mathrm{~h} 15 \mathrm{~m}$ \\
\hline 1.00 & $22 \mathrm{~h} 00 \mathrm{~m}$ & $15 \mathrm{~h} 10 \mathrm{~m}$ & $10 \mathrm{~h} 20 \mathrm{~m}$ & $8 \mathrm{~h} 00 \mathrm{~m}$ & $6 \mathrm{~h} 10 \mathrm{~m}$ & $4 \mathrm{~h} 50 \mathrm{~m}$ \\
\hline 2.00 & $100 \%$ & $69 \%$ & $47 \%$ & $36 \%$ & $28 \%$ & $22 \%$ \\
\hline $\begin{array}{c}\text { Percentage comparison } \\
\text { of carburisation times }\end{array}$ & $100 \%$ & & $69 \%$ & $28 \%$ \\
\hline
\end{tabular}

On the other hand, HPGQ enhanced significantly the quality of quenching results, especially with regard to distortions that can be significantly reduced. Gas cooling takes place in a single phase and in a much more regular manner with regard to a single detail. Additionally, the cooling rate can be adjusted freely by changing the gas pressure (density) and speed (fan rpm), making the process totally controllable. The modern HPGQ systems with nitrogen or helium under the pressure of 25 bar are just as efficient as cooling in oil and can fully replace it, thus taking over the same assortment of details and steel grades. Gas quenching eliminates the washing process and is fully environmentally-friendly.

The furnaces and low-pressure systems are compact, energy saving and environmentally-friendly devices. They are characterized by significant flexibility and can be turned on and off at any moment. Moreover, it takes only about an hour for such a device to achieve the process parameters. They also do not require atmosphere stabilization or conditioning and changing the technological parameters can be carried out practically immediately. The case hardening technology implemented in modern low-pressure furnaces is a precise, efficient, clean and environmentally friendly process.

In spite of elaboration and implementation of new technologies one important element remains unchanged and common with the traditional technology: the details are arranged into batches on dedicated hardware and they go through the whole heat treatment process in such configuration. This means that every detail in a batch is subject to the process conditions in an individual manner, characteristic for a given position, and achieves specific parameters when it comes to heating speed, temperature reached, process atmosphere composition and intensity and directionality of cooling. There is no doubt that the details located on the outside of the batch are going to heat up faster and up to a different temperature (according to the temperature distribution in the batch), are located in a 
"richer" atmosphere and are quenched more intensely in comparison to the details located on the inside. This results in a very wide distribution of case hardening process results in the details within a batch when it comes to e.g. surface and core hardness, microstructure and, particularly, effective layer thickness.

As a result of non-uniform cooling there occur large temperature differences between different places on the outside and inside of the elements, resulting in creation of thermal stresses and non-uniform microstructure transformations, which leads, in the end, to creation of major distortions of the shape of element quenched. The situation is additionally worsened by the fact that the stream of cooling medium becomes dispersed in the batch and every detail is under the influence of different, local cooling conditions. Batch quenching (especially in oil) can be summarized as an uncontrolled and non-uniform process that results in major distortions within the scope of a single details and their great uniqueness within the whole batch. The application of gas as a cooling agent may reduce the extent of distortions when compared to oil due to singlephase nature of convection cooling in gas, but there still persist all the negative consequences of batch quenching.

When summarizing the modern case, hardening technologies used on mass scale there have to be appreciated their advantages in the form of powerful efficiency and minimum costs of the process itself. Those technologies have been perfected for tens of years and mastered to a sufficient degree, but the possibilities for developing and improving them have been exhausted. The growing needs and requirements of modern industry within the categories of increase in quality, repeatability, flexibility, rate, process continuity, reduction in total productions costs and neutrality towards the natural environment cannot be met by employing the traditional ways.

\section{Experiments}

In general, the majority of shortcomings and limitations of traditional heat treatment can be related to its batch nature. In order to open new perspectives it is necessary to remove this factor and replace it with the opposite one, that is, the single-piece flow model. The single-piece flow concept in heat treatment for the mass production industry has been appearing for a longer while in theoretical deliberations, industry articles, readings and presentations $[20,21]$. There have been elaborated various system solutions more or less consistent with that idea. However, until now there has not been created any device that would conform to this idea in 100\% within the scope of mass heat treatment $[22,23]$. Single-piece flow case hardening should be understood as every single detail going through the same process conditions and positions as all of the individual details preceding and following it. As a result of analysis of previous structural solutions for steel element heat treatment devices there was suggested a new approach towards the essence of the problem, consisting in application of furnace design that has not been described in the literature or suggested by any heat treatment device manufacturers in the world yet $[24,25]$.

Within the framework of studies described in this article there have been carried out works on preparing a device with a new design for operation in low-pressure conditions and there have been started works on elaborating and implementing into such device a new lowpressure carburising technology, executed using a short pulse method, that would be optimal for this particular furnace design. There has been tested the capability of the device to carry out technical execution of low-pressure carburising processes by employing the short pulse method and subsequent high pressure gas quenching.

\subsection{Short-pulse low-pressure carburising}

The concept of short-pulse low-pressure carburising stems from the FineCarb low-pressure carburising technology that is well documented in the literature devoted to this subject [26-32]. In the FineCarb method the process is divided into a sequence of boost-diffusion saturation segment and holding segment pairs. During several-minute long boost segment the details remain in a chamber with a carboniferous gas. In holding segments that take from several to several dozen minutes the carboniferous gas is evacuated and the details are held in technical vacuum. In the short pulse method there is present only one pair of boost-diffusion segments, where the durations of both these segments are identical. At the boost stage the carburising gas is injected multiple times in short pulses, each taking a few seconds.

\subsection{System for single-piece flow treatment}

The new design solution includes three parallelly connected technological chambers with flow passage of individual details, configured in a horizontal system and located in common low-pressure space with gas-tight separation. The unloading gate has been integrated with a device for individual gas cooling of details in furnace 
operation cycle, which is easy to connect with an external tempering device. Thus, every detail passing through the process chambers with stable parameters is going to be subjected to identical process conditions.

Figure 1. presents the concept of a low-pressure furnace for case hardening of geared wheels or rings using lowpressure carburising (LPC) and high pressure gas quenching (HPGQ) that fully meets the conditions of single-piece flow technology and has all its advantages. The devices consist of 3 horizontal processing chambers intended, accordingly, for: heating, low-pressure carburising and diffusion and pre-cooling prior to quenching, a separate quenching chamber, used also for unloading, and a loading chamber. The transport of details between the chambers is provided by 2 vertical transport chambers installed on both sides of the system.

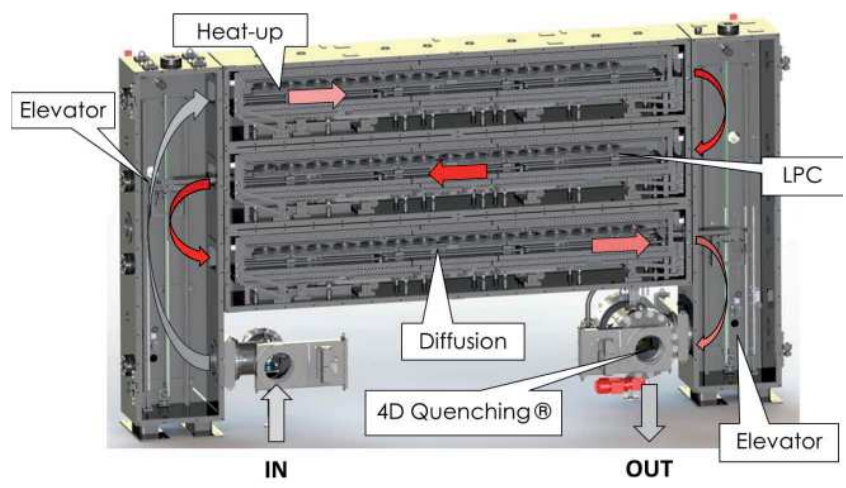

Fig. 1. Single-piece flow heat treatment furnace concept

The single-piece flow process progresses as follows: a single element (e.g. geared wheel) is placed into the loading chamber. Then it is transported and loaded into the heating chamber where it passes subsequently (by means of the walking beam shaft) through all the positions, achieving the required process temperature in the end. Afterwards it is transported to the low-pressure carburising chamber where, finally, the detail surface is saturated with the appropriate amount of carbon. Next, the element is transported to the diffusion chamber where the final carbon profile is shaped and the temperature is lowered prior to quenching. In the following sequence the element is transported to the gas cooling chamber, where it is quenched. The final operation consists in the element being unloaded from the quenching chamber (and subsequently directed to tempering). The same sequence/cycle applies to all the parts of a given series with identical process parameters and ensures high precision and repeatability of results. The improvement in quality and repeatability stems from every detail receiving the same process parameters: temperature and atmosphere. A single detail heats up in a faster and more uniform manner and facilitates temperature equalization through heat conductivity within the material. Additionally, the effect of non-uniformity of temperature in the whole process chamber at various positions is eliminated by averaging resulting from the element passing through all the positions.

The above design solution provides advantageous conditions for controlling and improving the extent of quenching deformations by using a high pressure gas cooling system dedicated to the shape of elements, installed in the quenching chamber. The basis of the system consists of a set of cooling nozzles surrounding the element and ensuring uniform inflow of cooling gas from all directions and a table rotating together with the detail, supporting the cooling uniformity. The nozzle-based cooling system employing nitrogen under the pressure of up to $1.5 \mathrm{MPa}$ allows obtaining cooling intensity comparable to that of oil systems without having to use helium. The whole solution enables optimal adjustment of cooling parameters and cooling nozzle configuration to the shape of the element in order to make the cooling uniform, which translates directly into reduction in distortions. In comparison to oil systems, such a solution ensures control and significant reduction in quenching distortions, as well as achieving high repeatability of results within a whole series of elements.

\section{Results}

The first actual system of the kind described above was built and installed in the R\&D hall of Seco/Warwick Europe in order to prove the assumed properties of the single-piece flow concept. It enables carrying out a complex case hardening process consisting of low-pressure carburising, gas quenching and hardening on geared wheels with diameter of 70-200 $\mathrm{mm}$, height of $50 \mathrm{~mm}$ and weight of up to $5 \mathrm{~kg}$. The carburisation processes can be carried out in high temperatures of up to $1100^{\circ} \mathrm{C}$. The process chambers have 15 positions for the largest diameter of parts, which enables carrying out processes with intervals as short as 1 minute. The system was checked comprehensively and in detail with regard to technical and technological matters and received a positive evaluation. The positive results within the scope of precision and repeatability in formation of hardened layers and control over and reduction of quenching distortions have been confirmed.

Within the framework of confirming the effect of the short-pulse carburising technology there was carried out a carburising process in the temperature of $1040^{\circ} \mathrm{C}$ with 
interval of ca. 3 minutes. The experiment was conducted on a series of geared crown wheels made of 18CrNiMo7-6 steel, with diameter of $180 \mathrm{~mm}$ and weight of $3.5 \mathrm{~kg}$, carburised on a $0.9 \mathrm{~mm}$ layer. All the hardness profiles measured on working parts of teeth from selected wheels of the series were matching. The spread of layer thickness measured amounted to $0.06 \mathrm{~mm}$ and was almost an order of magnitude lower than the required one, which testifies to the very high precision and repeatability of this process. Additionally, it has to be noted that with such a high precision the spread of results could be caused to a significant extent by the uncertainty in hardness measurement.

In Fig. 2. there are presented the quenching distortions measured before and after a process in the new device on geared wheels made of $20 \mathrm{MnCr} 5$ steel with external diameter of ca. $180 \mathrm{~mm}$ and weight of $1.5 \mathrm{~kg}$. The results apply to axial throw of the bottom surface of geared wheel crown before and after heat treatment. Prior to heat treatment the size of the axial throw was at the level of 0.01 $\mathrm{mm}$ and afterwards it increased to ca. $0.04 \mathrm{~mm}$ without exceeding the acceptable value of $0.05 \mathrm{~mm}$. A similar situation takes place when it comes to radial throw and pitch diameter, where the distortions remain within the requirements. This means that for the given wheel the finishing treatment could be totally eliminated or, alternatively, significantly limited.

In Fig.3. there are presented the results of uniformity and homogeneity carburisation investigations on geared wheel. The wheels were made of $20 \mathrm{MnCr} 5$ steel with external diameter of ca. $180 \mathrm{~mm}$ and weight of $1.5 \mathrm{~kg}$ as well.

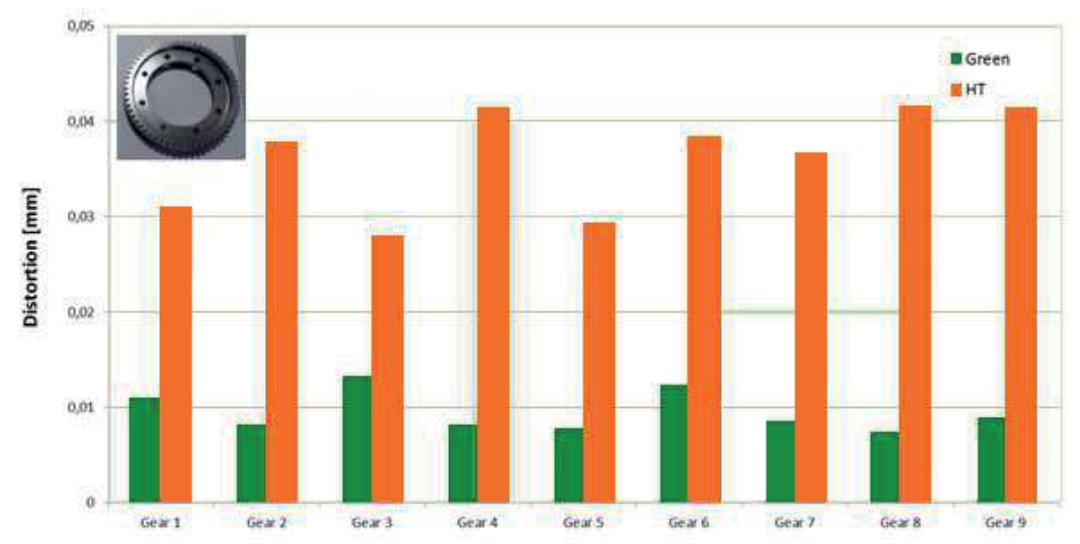

Fig. 2. Comparison of axial throw of the geared crown bottom surface on 9 wheel belonging to the series prior to heat treatment (green) and after heat treatment in the newly elaborated device (orange)

Uniformity and homogeneity

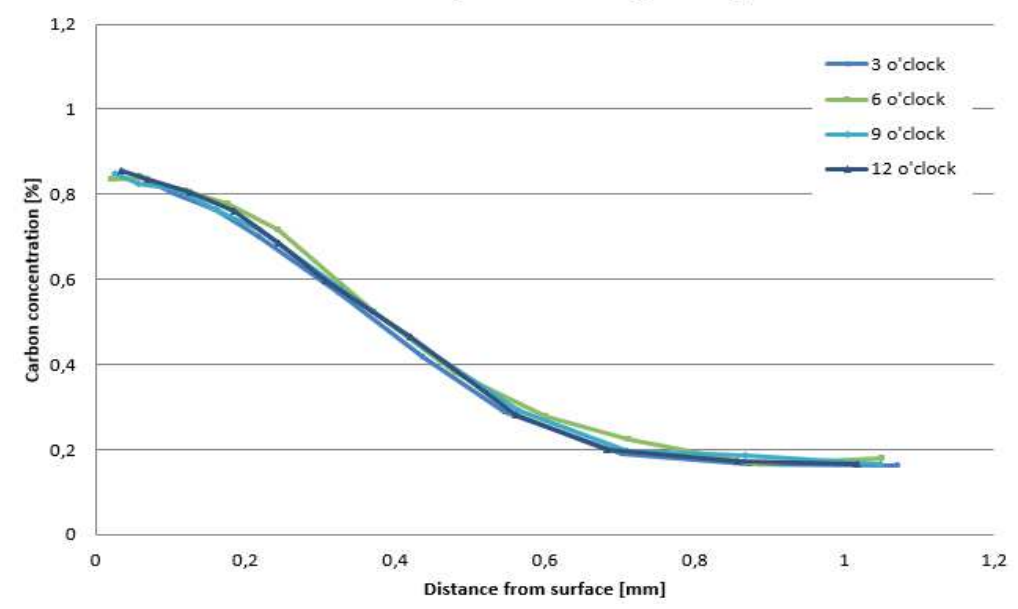

Fig. 3. The results of uniformity and homogeneity carburisation investigations on geared wheel (steel 20MnCr5) 


\section{Conclusions}

There has been confirmed the capability of the device to carry out technical execution of short-pulse low-pressure carburising processes and high pressure gas quenching.

The device resulting from research works is going to constitute a fully automated element of a manufacturing line, adjusted for the purposes of being included in the production process automatic control system.

\section{Acknowledgements}

The research and publication were financed by the National Centre for Research and Development as part of project no. POIR.04.01.04-00-0087/15 entitled: "Equipment for high performance and precise heat treatment with a quenching deformation reduction system for direct application in downstream production chains of mechanical gearing and bearings."

\section{References}

[1] IWT (Institut fur Werkstofftechnic), Economic consequences of distortion, Bremen, 1995.

[2] D. Herring, Understanding Component Failures. Part 1: Mechanisms, Industrial Heating 7 (2013) 16-18.

[3] D. Herring, Understanding Component Failures. Part 2: Analysis Methods, Industrial Heating 8 (2013) 18-20.

[4] D. Wulpi, Understanding How Components Fail, ASM International, Materials Park, 2013.

[5] D. Herring, Atmosphere Heat Treatment, Volume I, BNP Media Group, 2014.

[6] H. Chandler, Heat Treater's Guide: Practices and Procedures for Irons and Steels, ASM International, Materials Park, 1995.

[7] D. Herring, What Happens to Steel during Heat Treatment? Part One: Phase Transformations, Industrial Heating 4 (2007) 12-14.

[8] D. Herring, What Happens to Steel during Heat Treatment? Part Two: Cooling Transformations, Industrial Heating 6 (2007) 12-14.

[9] D. Herring, Vacuum Heat Treating, BNP Medial Group, 2014.

[10] M. Korecki, P. Kula, J. Olejnik, New Capabilities in HPGQ Vacuum Furnaces, Industrial Heating, 3, 2011.

[11] M. Korecki, J. Olejnik, Z. Szczerba, M. Bazel, Singlechamber HPGQ Vacuum Furnace with Quenching Efficiency Comparable to Oil, Industrial Heating 9 (2009) 73-77.
[12] D. Herring, Technology Trends in Vacuum Heat Treating. Part One: Markets, Processes and Applications, Industrial Heating 10 (2008) 83-88.

[13] D. Herring, Technology Trends in Vacuum Heat Treating. Part Two: Processes and Applications, Industrial Heating 11 (2008) 57-62.

[14] D. Herring, Technology Trends in Vacuum Heat Treating. Part Three: New Technologies and Future Developments, Industrial Heating 1 (2009) 44-46.

[15] P. Kula, R. Pietrasik., K. Dybowski, M. Korecki, J. Olejnik, PreNit LPC - the Modern Technology for Automotive, Proceedings of the New Challenges In Heat Treatment and Surface Engineering, DubrownikCavtat, Croatia, 2009, 165-170.

[16] M. Korecki, P. Kula, E. Wołowiec, M. Bazel, M. Sut, Low-pressure Carburizing (LPC) and Low-pressure Nitriding (LPN) of Fuel Injection Nozzles made of Tool Steel, IFHTSE, Dubrovnik-Cavtat, Croatia, 2013, 69-76.

[17] M. Korecki, M. Bazel, M. Sut, P. Kula, E. WołowiecKorecka, LPC and LPN of Tool Steel Fuel Injection Nozzles, Industrial Heating 6 (2014).

[18] P. Kula, R. Atraszkiewicz, E. Wołowiec, Modern Gas Quenching Chambers supported by SimVaC Plus Hardness Application, Industrial Processing 3 (2008) 55-58.

[19] M. Korecki, E. Wołowiec-Korecka, W. Stachurski, A. Brewka, M. Sut, M. Bazel, Increased efficiency and productivity. Successful applications based vacuum carburizing furnaces CaseMaster Evolution and UniCase Master, Proceedings of the XIX Seminar Group S/W, Mierzęcin, 2016, 145-153.

[20] G. Vasilash, The Auto Industry \& Gear Making, Modern Machine Shop 9 (2013).

[21] V. Marinov, Manufacturing Technology, 2004.

[22] V. Heuer, K. Löser, G. Schmitt, K. Ritter, One Piece Flow - Integration of Case Hardening into the Manufacturing Line, Proceedings of the Conference on Gears, TUM, Garching, Germany, 2010.

[23] IHI, In-Line Heat Treatment - Next Generation Heat Treatment Equipment, IHI Engineering Review 44/2 (2011).

[24] A. Kohara Gear Industry Co, Introduction to Gears, Nakacho, 2006.

[25] G. Parrish, Carburizing: Microstructures and Properties, ASM International, Materials Park, 1999.

[26] P. Kula, J. Olejnik, J. Kowalewski, FineCarb - The smart system for vacuum carburizing. Heat Treating \& Hardening of Gears 3 (2004) 1-10.

[27] P. Kula, R. Pietrasik, K. Dybowski, Vacuum carburizing - process optimization, Journal of Materials Processing Technology 164/165 (2005) 876-881. 
[28] P. Kula, M. Korecki, R. Pietrasik, E. Wołowiec, K. Dybowski, Ł. Kołodziejczyk, R. Atraszkiewicz, M. Krasowski, FineCarb - the flexible system for lowpressure carburizing. New options and performance, Journal of The Japan Society for Heat Treatment 49/1 (2009) 133-136.

[29] M. Korecki, J. Olejnik, P. Kula, R. Pietrasik, E. Wołowiec, Hornosc de vacio LPC+LPN+HPGQ 25 bar $\mathrm{N}_{2} / \mathrm{He}$, Tratamientos termicos 124 (2011) 17-21 (in Spanish).
[30] P. Kula, K. Dybowski, E. Wołowiec, R. Pietrasik, Boost-diffusion vacuum carburizing - process optimisation, Vacuum 99 (2014) 175-179.

[31] M. Korecki, P. Kula, E. Wołowiec, M. Bazel, M. Sut, Low-pressure carburizing and nitriding of fuel injection nozzles, Heat Processing 3 (2014) 59-62.

[32] E. Wołowiec, P. Kula, Ł. Kołodziejczyk, K. Dybowski, M. Korecki Mathematical modelling of the vacuum carburizing process, Thermal Processing for Gear Solutions 3/4 (2014) 34-40. 